\title{
Geopolymers from mining tailings for more sustainable raw material supply
}

\author{
Robert Obenaus-Emler ${ }^{1 *}$, Mirja Illikainen $^{2}$, Mahroo Falah $^{2}$, Päivi Kinnunen ${ }^{3} \&$ Kari Heiskanen ${ }^{4}$ \\ ${ }^{1}$ Montanuniversitaet Leoben, Chair of Ceramics, 8700 Leoben, Austria \\ ${ }^{2}$ University of Oulu, Fibre and particle engineering research unit, 90014 University of Oulu, Finland \\ ${ }^{3}$ VTT Technical Research Centre of Finland, Material processing and geotechnology, Espoo, Finland \\ ${ }^{4}$ Outotec Finland Oy, Finland
}

\begin{abstract}
For ecologic and economic reasons tailings, waste rock and water management become progressively important factors in the mining industry. The European Union funded project 'Integrated mineral technologies for more sustainable raw material supply' (ITERAMS) aims to (1) close the water cycle of the mineral processing plant (i.e. minimizing the release of wastewater to the adjacent environment), and (2) to use tailings (and waste rock) as raw materials for geopolymers. This will (1) enable significantly more efficient water recycling at the mining sites, (2) deliver cost savings and added income due to the valorisation of solid waste residues, and (3) minimize the overall environmental footprint of the mining industry and will therefore help improving its performance and as a consequence its social position. The developed solutions influence the total lifecycle of the mining operation, as they provide input to project planning and operational phases as well as to the closure and recultivation. In this paper, the valorisation of the tailings and the waste rock is discussed. The main applications of the geopolymer products are (1) backfill material to fill open cavities from the mining operation and (2) a cover for surface deposits of tailings to store them environmentally safe - i.e. seal them off from surface water streams and oxidising conditions.
\end{abstract}

\section{Background}

When a mine is developed for access to the ore-body, host rock has to be mined and subsequently stored. The amount of waste rock varies much depending on the ore formation and whether the ore is mined from an open-pit or an underground mine. Due to geological reasons, even the mined ore itself contains some valueless host rock and some ore might be left behind in the mine due to low grades or other economic reasons. The waste rock dilution can be substantial leading to increased processing costs and tailings amount but no revenue.

Therefore one of the major environmental issues related to mining activities is the waste streams that can reach over $90 \%$ of the total mass. When using a flotation process in mineral processing this waste stream (i.e. tailings), is a thick slurry mixture of different minerals, process chemicals, and water. Up to now little effort has been made regarding the valorisation of the tailings and they are normally deposited as such.

Depositing tailings in storage systems on the surface can lead to various problems:

1. When tailings contain sulphide minerals, such as pyrite $\left(\mathrm{FeS}_{2}\right)$ and pyrrhotite $\left(\mathrm{Fe}_{1-\mathrm{x}} \mathrm{S}\right)$, oxidation in the presence of oxygen and water (either from rain or from mineral processing) results in formation of sulphuric acid that - if not being captured - leads to severe ecological problems (AMD - acidic mine drainage).

2. The huge amount of tailings results in very large deposits on the surface, which the authorities do not permit any more or a suitable large space cannot be found or is strongly opposed by the communities close to the mine.

3. When dams are used for the deposit a dam failure can result in an ecological disaster [1].

As a consequence the disposal of mine tailings is a major environmental liability, becoming increasingly important for current and future mining operations especially on ore bodies with low grades. In order to prevent the problems related to tailings storage, new approaches are needed.

The ITERAMS project "Integrated Mineral Technologies for More Sustainable Raw Material Supply" funded by the European Union's Horizon 2020 programme aims to reinvent water and waste management in mining. The new methods developed in the project will offer the European mining industry the potential to strengthen its position in the forefront with regard to minimal waste, minimal energy, and minimal water consumption in the mining sector.

Regarding the tailings management the ITERAMS project focuses on the geopolymerisation or alkali-

* Corresponding author: emler@unileoben.ac.at 
activation of mine tailings and targets new, sustainable solutions for tailings utilization and storage. Figure 1 schematically depicts the geopolymerisation of tailings and solid waste materials within the framework of the ITERAMS project. It is obvious that a successful water management (i.e. recirculation of process water) and an effective tailings management strongly rely on one another and have a high impact on the environmental footprint of a mining operation.

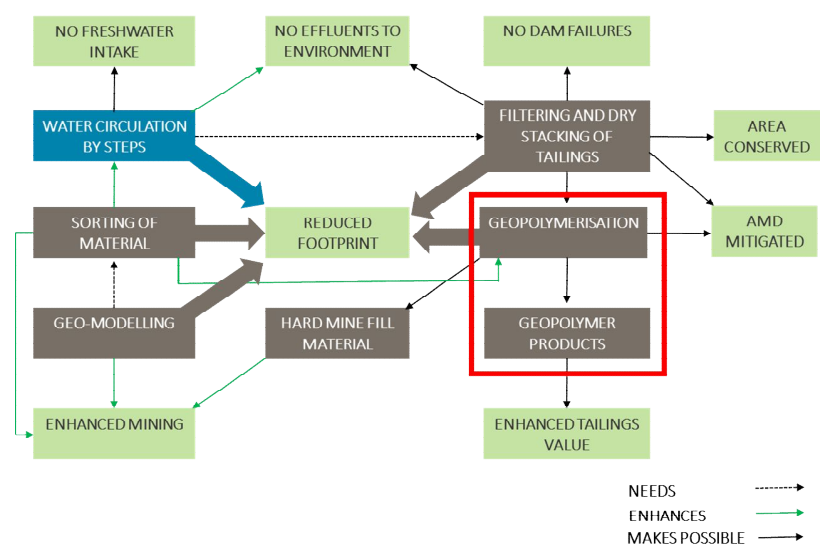

Fig. 1. Geopolymerisation of mine tailings in the framework of the ITERAMS project. AMD (acidic mine drainage) refers to the formation of acidic solutions originating from the deposition of sulphur containing ores when in contact with water under oxidising conditions.

\subsection{Mine tailings}

Mine tailings from a flotation process refer to a heterogeneous mixture that contains fine solids (minerals) suspended in process-contaminated water after the valuable fraction has been extracted from the uneconomic fraction (gangue) of the mined ore. The fine intergrowth of minerals in an ore essentially influences the particle size distribution required to liberate the valuable minerals from the gangue in the mineral processing process and consequently the fineness of the solids in the tailings. In general, the tailings show a very fine overall particle size distribution with a maximum particle size of around $100 \mu \mathrm{m}$ and around $50 \%$ smaller than $20 \mu \mathrm{m}$ - in many cases even finer particle size distributions can be expected. The particle size distribution of the tailings is therefore roughly similar to the particle size distribution of ordinary Portland cement.

Additionally to the solid minerals the tailings slurry contains different soluble species including dissolved metals and chemical reagents used in the flotation process $[2,3]$. The tailings slurry is typically discharged into lagoons, ponds or closed mine sites, in which solids and process water are separated under gravity [3]. Physical and chemical characteristics of tailings depend on the ore type and selected production process [2]. Fresh tailings tend to be dominated by silicates, carbonates and sulphides [4].

It is estimated that 5 - 7 billion metric tons of tailings are produced annually worldwide with significantly higher amounts already stored [2]. Onuaguluchi and Eren estimated that in 2011 approximately 2 billion metric tons of copper tailings alone were produced globally [5]. For example in copper mining, 95-99\% of the crushed ore can end up in the tailings [2]. Due to the declining ore grades, the amount of tailings is expected to further increase in the upcoming years.

If tailings contain some remaining sulphide minerals, they can oxidise in the presence of oxygen and water to produce sulphuric acid and subsequently leach metals and sulphates from tailings thus creating a potential environmental problem [2, 4]. As discharged tailings represent a long-term liability issue to mining companies, new solutions for the valorisation of the tailings should be developed. Technical as well as economic and environmental requirements need to be met in the context of the mineral processing process (e.g. particle size distribution, valuable ore recovery rate, concentrate grade) and mining operation in general.

\subsection{Geopolymers and geopolymerisation}

Geopolymers are materials produced at alkaline conditions from solid aluminosilicate materials. The suitable precursors are natural clays and different industrial residues. The produced geopolymer is a solid material comparable to ceramic or hardened Portland cement. Geopolymers show many favourable properties such as rapid setting and hardening, excellent bond strength, good long-term properties and durability, a good ability to immobilize toxic metals and stabilize hazardous substances, and improved resistance to acids and elevated temperatures compared to ordinary Portland cement. [6,7]

Initially metakaolin was used as a raw material for geopolymers and has become a model compound for the comparison with other precursor materials. In recent years a number of other raw material sources (e.g. fly ash, natural minerals, metallurgical wastes as well as their mixtures) have been studied to synthesize geopolymers [8].

Geopolymers can be produced at room temperature or slightly elevated temperatures with low energy consumption and they have shown $80 \%$ lower $\mathrm{CO}_{2}$ emissions than traditional concrete with comparable mechanical properties [7]. The main principles of geopolymerisation are schematically described in Figure 2. During the alkali activation, silicon and aluminium ions are dissolved from the aluminosilicate raw material into the solution. These dissolved silicon and aluminium hydroxide molecules undergo a polymerisation reaction forming a new $\mathrm{Si}-\mathrm{O}-\mathrm{Si}$ or $\mathrm{Si}-\mathrm{O}-$ $\mathrm{Al}$ bonds producing the final 3D amorphous or semicrystalline silico-aluminate structure $[7,8]$. Silicon and Aluminium are in IV-fold coordination as $\mathrm{SiO}_{4}$ and $\mathrm{AlO}_{4}$ tetrahedra linked by sharing all oxygen atoms. This leads to a negative charge in the geopolymer network which is balanced by sufficient cations in the framework cavities $\left(\mathrm{Na}^{+}, \mathrm{K}^{+}\right.$and $\left.\mathrm{Ca}^{2+}\right)$ originating from the alkaline activator or the raw materials itself. Geopolymers can be empirically expressed as $\mathrm{Mn}_{\mathrm{n}}\left(-\left(\mathrm{SiO}_{2}\right)_{\mathrm{z}}-\left(\mathrm{AlO}_{2}\right)_{\mathrm{n}} \cdot \mathrm{wH}_{2} \mathrm{O}\right.$, where $\mathrm{M}$ is an alkali element, $\mathrm{z}(1,2$, or 3$)$ is related to the structure, and $\mathrm{n}$ is the degree of polymerisation [8]. 


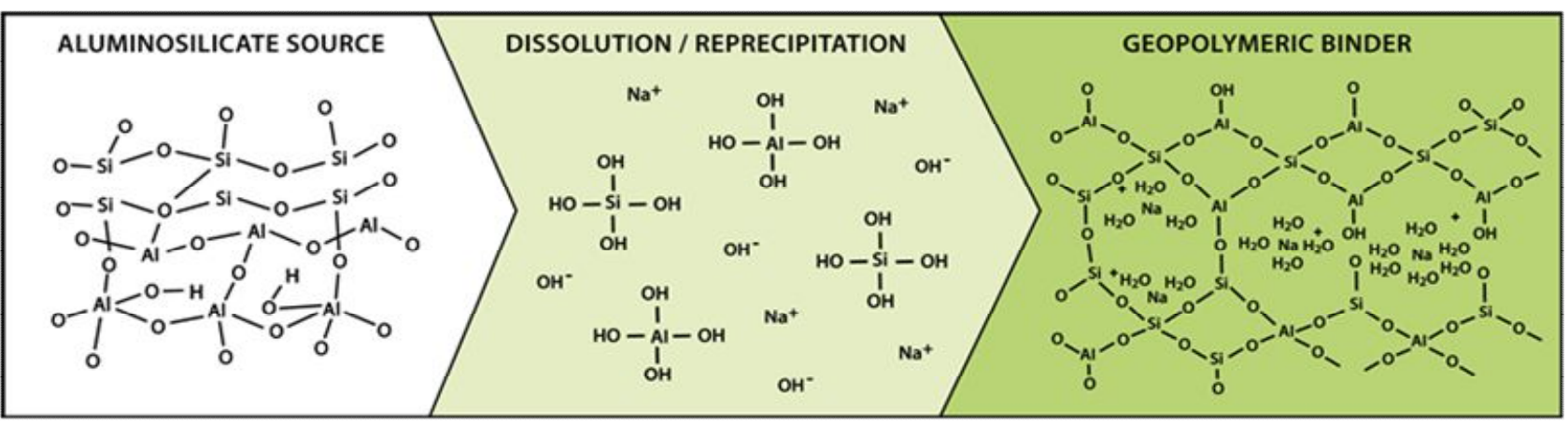

Fig. 2. Schematic representation of the geopolymerisation process - Aluminium and silicon ions are dissolved in an alkaline solution (here: $\mathrm{NaOH}$ ) and re-polymerized to form a solid geopolymer network.

The process of geopolymerisation has also been explored as a potential method for tailings consolidation and heavy metal fixation. The tailings of many existing mining operations contain the aluminosilicate minerals needed for geopolymerisation at least to some extent and therefore offer an interesting alternative source material for geopolymer materials [8]. Even though natural rock can be thought of as a rather non-reactive material, the fine particle size distribution of the tailings might be advantageous in enhancing the reactivity via additional processes.

\section{Tailings management in the ITERAMS approach}

The ITERAMS project will focus on understanding the reactivity of different tailings fractions (depending on their mineralogical composition) and the relationship between the precursor's properties and the microstructure of formed geopolymers.

The resulting geopolymers can be used directly at the mine site as (1) a back fill material to fill underground cavities or (2) a covering layer for surface deposits of tailings. Depending on their properties the geopolymers could also be used for other applications (e.g. construction industry).

The best-case scenario resulting from the project leads to a mining activity without any needs to deposit tailings on the surface or a minimized amount of tailings deposited on the surface using a covering layer for safely storing the tailings shielded from environmental conditions. Hence mining operations will be more ecologically friendly and probably even more economically feasible.

Additional investigations on synthetic tailings will help to understand the influence of various minerals regarding their contribution to the process of geopolymerisation.

\subsection{Mineral precursors}

The key parameters influencing the value of a particular waste as a source material for geopolymers are the content of reactive silica and alumina, $\mathrm{Fe}_{2} \mathrm{O}_{3}$ and $\mathrm{CaO}$, as well as the content of the vitreous phase, and the particle size distribution. The ratio of silicon to aluminium is a crucial parameter for the formation of a geopolymer network and should lie between 2.5 and 4 [7]. Since for the applications of geopolymers at the mine site a high mechanical strength is not necessarily required a higher ratio of silicon to aluminium may be tolerated. This would mean that not all the silicon is incorporated into the geopolymer network. In the presence of $\mathrm{Ca}^{2+}$ ions (dissolved from the raw materials) calcium silicate hydrate $(\mathrm{CSH})$ gels similar to ordinary Portland cement might be formed additionally. Previous studies have shown that mine tailings with a ratio of silicon to aluminium of up to 5 can still be used as a suitable raw material for geopolymers [8]. For mine sites that do not contain a high amount of aluminium in their minerals the addition of an external source of aluminium (e.g. aluminate solutions) has to be considered.

The ITERAMS consortium and its industrial partners offer the unique possibility to not only assess the tailings itself but also sample different locations at selected mine sites in order to assess various natural minerals for their suitability as raw material sources for a subsequent geopolymerisation of tailings and waste rock. This will ultimately lead to a more fundamental understanding of various minerals and mineral mixes as precursors for geopolymers.

\subsection{Pre-treatment of mining tailings}

Not all minerals included in tailings might be advantageous for the formation of geopolymers in their original state but could contribute if pre-treated. Furthermore, the distribution of certain minerals with respect to the particle size distribution will be studied in order to get a better understanding of possible supplemental mineral processing procedures (e.g. classification, additional grinding, and additional flotation process).

Additional mechanisms to increase the reactivity of the tailings are thermal or thermo-chemical methods. As stated above different particle size fractions of the tailings might need different pre-treatment in order to be used as a geopolymer precursor - e.g. coarser fractions might show increased reactivity after grinding. 


\subsection{Alkali-activation}

The activation by alkaline solutions significantly affects the geopolymerisation by leaching silicon and aluminium from the raw material precursors, the formation of an aluminosilicate glassy gel, and the subsequent condensation process. The alkali activators can be divided into two groups: (1) alkalis of the $\mathrm{MOH}-$ and $\mathrm{M}_{2} \mathrm{CO}_{3}$-type, and (2) silicate additives of the $\mathrm{M}_{2} \mathrm{SiO}_{3}$-type, where $\mathrm{M}$ is an alkali element. They can be used independently or in combination [8, 9-11]. In most cases, the alkaline activator is dissolved in water before added to the solid raw materials.

The proper selection of the alkali activator type as well as their concentration is essential for the geopolymerisation reactions, and therefore significantly influences the mechanical and chemical properties of the resulting geopolymer products.

\subsection{Target applications}

The production of geopolymers from tailings offers possibilities to make valuable products to be used directly at the mine site. In case the tailings show a higher potential another option is to sell them as raw material for more enhanced geopolymer products.

Tailings can be used as a geopolymer binder system for backfill of open cavities from underground mining activities. They can be applied as a standalone paste backfill or in combination with waste rock. Here the mechanical and thermo-mechanical properties of the resulting geopolymers are of interest and will be adjusted to fit specifications related to the mining operation and design. Additionally, the properties of the geopolymer slurry (i.e. pumpability, setting time) have to be adjusted according to the needs for refeeding the paste back into the mine especially with regard to the distance of the geopolymer mixing and the actual place of installation underground. Generally, backfilling open underground cavities results in a high ore recovery increases the occupational safety during the mining operation, and reduces surface waste disposal.

Wherever the complete use of the tailings as backfill is not possible the remaining tailings may have to be stored in deposits on the surface. If the tailings contain sulphide minerals they have to be sealed from surface water flows and oxidising conditions in order to avoid the formation of sulphuric acid and subsequent environmental pollution (acidic mine drainage). It is intended to use a covering layer of geopolymers produced from the tailings to provide a solid and safe protection which can also assist subsequent land recultivation. For this application, the water penetration and the permeability of oxygen are crucial factors for the proper functionality of the installed covering layer. Additionally, the mechanical properties have to be adjusted in order to withstand the environmental conditions on site in order to prevent cracking of the covering layer. Generally, geopolymers are known to show little penetration of water which makes them an ideal material for this purpose.
Additionally mine tailing can be applied as geopolymer precursors for the production of eco-friendly construction materials (e.g. bricks, ceramic tiles, etc.). Copper mine tailings have shown great potential as an additive in construction materials [5].

\section{Conclusions}

Geopolymers have been studied to some extent in the past decades. Aluminate- and silicate- containing materials or minerals can react in alkaline conditions, yielding a solid material comparable to concrete. Geopolymers appear to be a very promising material since they are an environmentally friendly and technically competitive alternative to ordinary Portland cement.

The ITERAMS project will increase the understanding of the reactivity of different tailings fractions (and their mineralogical composition respectively) regarding the alkali activation and formation of geopolymers. Additionally, the relationship between the properties of the precursor and the microstructure of formed geopolymers will be studied on a fundamental basis. A better understanding of the requirements for geopolymerisation of mine tailings enables to create an integrated approach for tailings management, where the mining and mineral processing process can be proactively modified to fit the needs of tailings valorisation.

The results from laboratory tests will help the design of geopolymer mixes for different applications. Additionally to geopolymer mix recipes a list of 'favourable' minerals and 'unfavourable' minerals (that might need to be removed from the tailings) will be available at the end of the project.

Developed ITERAMS concepts and technologies regarding tailings and water management are jointly validated by industrial and research partners at partners' mine sites. These technologies will be relevant also for other mining operations in the EU as well as globally. The impact of ITERAMS will promote new mining practices and the development of novel technologies to store and utilize mine tailings and solid waste.

\section{Acknowledgements}

This project has received funding from the European Union's Horizon 2020 research and innovation programme under grant agreement No 730480 .

\section{References}

1. D. Kossoff, W.E. Dubbin, M. Alfredsson, S.J. Edwards, M.G. Macklin, K.A. Hudson-Edwards, Appl. Geochem. 51, 229-245 (2014)

2. M. Edraki, T. Baumgartl, E. Manlapig, D. Bradshaw, D.M. Franks, C.J. Moran, J. Clean. Prod. 84, 411-420 (2014)

3. C. Wang, D. Harbottle, Q. Liu, Z. Xu, Miner. Eng. 58, 113-131 (2014) 
4. M.B.J. Lindsay, M.C. Moncur, J.G. Bain, J.L. Jambor, C.J. Ptacek, D.W. Blowes, Appl. Geochem. 57, 157-177 (2015)

5. O. Onuaguluchi, Ö. Eren, Constr. Build. Mater. 37, 723-727 (2012)

6. V.D. Glukhovsky, Proceedings of the $1^{\text {st }}$ International Conference on Alkaline Cements and Concretes (Kiev), 1-9 (1994)

7. J. Davidovits, Proceedings of the $1^{\text {st }}$ International Conference on Alkaline Cements and Concretes (Kiev), 131-149 (1994)

8. F. Rao, Q. Liu, Min. Proc. Ext. Met. Rev. 36, 399409 (2015)

9. P. Duxson, J.L. Provis, G.C. Lukey, J.S.J. van Deventer, Cem. Concr. Res. 37, 1590-1597 (2007)

10. P. Duxson, A. Fernández-Jiménez, J.L. Provis, G.C. Lukey, A. Palomo, J.S.J. van Deventer, J. Mater. Sci. 42, 2917-2933 (2007)

11. A. Fernández-Jiménez, A. Palomo, M. Criado, Cem. Concr. Res. 35, 1204-1209 (2005) 